\title{
PARAGUAY: INTERRUPCIÓN AL PROCESO DE CONSOLIDACIÓN DE LA DEMOCRACIA
}

\author{
Paraguay: A Democracy Consolidation Process Interrupted
}

\author{
LILIANA ROCÍO DUARTE RECALDE \\ Centro de Políticas Públicas Universidad Católica "Nuestra Señora de la Asunción".
}

\begin{abstract}
RESUMEN
En esta oportunidad se analizan los eventos más resaltantes que marcaron la realidad paraguaya en 2012, con énfasis en la destitución de Fernando Lugo en junio, sus antecedentes y consecuencias. Siguiendo a una semblanza de la coyuntura económica, se examina cómo el enardecimiento del conflicto por el acceso a la tierra fue el trasfondo social en que se desarrolló la destitución de Lugo via un juicio político. Se incluye también un análisis de los principales actores involucrados en las elecciones internas, realizadas con miras a las elecciones generales de abril de 2013. Finalmente, en consideración a los principales factores mencionados a lo largo del trabajo, se concluye que la democracia paraguaya en la actualidad sigue siendo de baja calidad y presenta mayores señales de retroceso que de consolidación.
\end{abstract}

Palabras clave: Democracia, estabilidad económica, conflicto social, polarización, elecciones internas.

\begin{abstract}
This paper discusses the main political events that took place in Paraguay during the year 2012, focusing primarily on President Fernando Lugo's dismissal from office in June and exploring both the factors that led to this incident as well as its consequences. Following $a$ commentary about the country's economic situation, the paper examines the growing conflict over access to arable land in Paraguay and the social background for Lugo's removal via impeachment. An analysis of the main actors involved in the primary elections, carried out in anticipation of the general elections that will take place in April 2013, is also included. Taking into account the points discussed in this paper and considering their influence on the overall quality of Paraguayan democracy, the conclusion is that its quality remains low and that there are signs that it may be receding rather than consolidating.
\end{abstract}

Key words: Democracy, Economic Stability, Social Conflict, Polarization, Primary Elections. 


\section{INTRODUCCIÓN}

El 22 de junio de 2012 se destituyó de la Presidencia de la República a Fernando Lugo, primer Presidente no perteneciente al Partido Colorado (Asociación Nacional Republicana, ANR) en más de seis décadas, faltando solo nueve meses para las siguientes elecciones generales. Su destitución llegó como consecuencia de un juicio político impulsado por el Parlamento, bajo argumento de que Lugo había demostrado mal desempeño en sus funciones y que ameritaba ser destituido, aunque sin presentar prueba alguna que sustentara cuatro de los cinco puntos incluidos en el libelo acusatorio. El mencionado procedimiento fue llevado a cabo menos de un día después de haber sido aprobada su realización, tiempo que la parte acusada consideró insuficiente para la preparación de la defensa y su exposición, siendo efectuado el juicio en forma de trámite apresurado que se correspondía con una sentencia conocida de antemano.

Dada su inmediatez y el efecto político desestabilizador que tuvo en consecuencia, la destitución de Lugo fue considerada como un "golpe de Estado parlamentario" (Duré et al., 2012) por parte de la ciudadanía, ${ }^{1}$ que estimó al proceso en su totalidad como ilegítimo aunque el mismo haya estado abrigado por un ropaje de legalidad. Lo ocurrido fue condenado también por los demás países del Mercado Común del Sur (MERCOSUR) y de la Unión de Naciones Suramericanas (UNASUR), que procedieron a suspender al Paraguay de estos bloques, a la vez que fue reprobado por gran parte de la comunidad internacional que, representada en los organismos internacionales, hasta el final del año 2012 se negaba a reconocer oficialmente a Federico Franco como Presidente legítimo del Paraguay. A pesar de que existieron manifestaciones públicas en contra de lo ocurrido a nivel nacional (E'a, 2012) como internacional (E'a, 2012a), las mismas no llegaron a surtir más efecto que el testimonial, lo que redundó en que se mantenga cierta sensación de estabilidad política a nivel doméstico y permitió que el debate gire, poco tiempo después, en torno a la agenda electoralista de los partidos políticos.

La destitución de Fernando Lugo marcó un punto culminante en el año, que bien puede considerarse el punto culminante en la historia política del Paraguay desde el golpe de Estado que puso fin a la dictadura de Stroessner en 1989, el cual había abierto paso para la obtención de libertades políticas y civiles por parte de la población paraguaya. Sin embargo, más allá de ese momento, 2012 fue un año cuya extensión estuvo marcada por un nivel de agitación social particular, que advierte una situación de crisis en el proceso de institucionalización de la democracia paraguaya. En esta oportunidad se realizará el análisis de los aspectos más salientes de la realidad económica, social y política que caracterizaron al Paraguay en 2012, contraponiendo una coyuntura económica que se mantuvo sin sobresaltos a la intensificación de la conflictividad social, en el marco de una dinámica política centrada en la competencia electoral con miras a las elecciones generales de 2013. 
Con el objetivo de ilustrar adecuadamente la situación coyuntural se presenta una semblanza de cómo han evolucionado los principales indicadores económicos y sociales en el periodo 2008-2012, a la vez que se hace referencia a hechos puntuales acontecidos en años anteriores y algunos ocurridos ya a principios de 2013, sin cuya mención se lograría una percepción inexacta del equilibrio de fuerzas políticas de cara a las elecciones generales a realizarse en abril. Finalmente, se propone esbozar una caracterización de la calidad de la democracia paraguaya, teniendo en cuenta los datos analizados.

\section{ESTABILIDAD ECONÓMICA}

El año 2012 estuvo marcado por un leve declive en los principales indicadores económicos, en comparación con los años anteriores, aunque predominó un clima de estabilidad. En atención a las condiciones macroeconómicas desfavorables, el Ministerio de Hacienda procedió a la aplicación de una política fiscal contracíclica para paliar la caída de la actividad económica. De acuerdo con informes del Banco Central del Paraguay (BCP, 2012), el sistema financiero continuó sólido, con bajos niveles de morosidad, buena liquidez, elevada capitalización y con una rentabilidad por encima de la variación nominal del Producto Interno Bruto (PIB). Además, persiste la posibilidad de realizar proyectos de inversión a largo plazo como resultado de la estabilidad macroeconómica producida por el equilibrio fiscal mantenido desde 2004.

Mientras que a nivel regional el crecimiento del PIB estuvo por encima del crecimiento mundial esperado, la economía paraguaya cerró el año con crecimiento negativo, registrándose un déficit de 1,2\% del PIB relacionado con la merma en la producción agrícola producida por la sequía, especialmente en los cultivos de soja, maíz y girasol. A su vez, el brote de fiebre aftosa verificado en septiembre de 2011 y el resultante cierre de mercados de destino para la carne incidió en los menores niveles de faenamiento realizados durante la primera parte del año, que se revertirían recién en el segundo semestre. En contrapartida, los sectores secundario y terciario crecieron en torno al 4,7\% y 6,1\% respectivamente (Cuadro 1), este último impulsado por la oferta de servicios de telecomunicaciones y financieros, lo que impidió una retracción mayor de la economía.

Cuadro 1: Tasa de crecimiento real del PIB por grandes sectores (\%)

\begin{tabular}{lcrrrr}
\hline \multicolumn{1}{c}{ Sectores } & 2008 & 2009 & 2010 & 2011 & 2012 \\
\hline Primario & 9,2 & $-17,2$ & 34,1 & 3,7 & $-20,0$ \\
Secundario + Binacionales & 6,6 & $-1,9$ & 4,1 & 3,0 & 4,7 \\
Terciario & 4,8 & 2,2 & 9,0 & 5,8 & 6,1 \\
Impuestos & 5,0 & $-1,0$ & 12,0 & 3,0 & $-0,5$ \\
PIB Total & 6,4 & $-4,0$ & 13,1 & 4,3 & $-1,2$ \\
\hline
\end{tabular}

Fuente: BCP, Informe Económico Preliminar 2012. 
Los gastos de consumo doméstico en bienes duraderos y los gastos de inversión fueron débiles, lo que se tradujo en el desarrollo poco dinámico de la demanda agregada y la escasa generación de nuevos empleos; hasta el tercer trimestre de 2012 la tasa de actividad laboral se situaba cerca del $62,7 \%$, alcanzando la tasa de desempleo abierto al $6,9 \%$, mientras que el subempleo afectaba a $19 \%$ de la población económicamente activa (DGEEC, 2012). No obstante, la recaudación registrada por la Subsecretaría de Estado de Tributación (SET, 2012a) entre enero y diciembre se incrementó en 11,8\% con relación a la recaudación del año anterior, mientras se contaba con 39.202 nuevas inscripciones en el Registro Único de Contribuyentes (RUC) hasta septiembre.

Luego de más de ocho años de cerrar las cuentas públicas con superávit, para el cierre de 2012 se proyectaba un déficit fiscal correspondiente al 3\% del PIB relacionado con el aumento dispuesto por el Parlamento en gastos principalmente rígidos, que representan 98\% del Presupuesto General de Gastos. Su financiamiento se apoyará en fondos obtenidos de préstamos internacionales, bonos del tesoro colocados a través de la bolsa de valores y un préstamo del Banco Central del Paraguay (BCP). Dado que la presión tributaria corresponde apenas a $12 \%$ del PIB y se mantiene como una de las más bajas de la región, la perspectiva de endeudamiento fiscal es creciente.

En lo que respecta a la dinámica comercial del Paraguay con el MERCOSUR, este bloque se constituye aún en el principal socio comercial del país y mediante su presencia en el mismo se ha logrado potenciar las exportaciones del Paraguay hacia otros mercados de la región. Las exportaciones paraguayas al bloque representan $18 \%$ del total exportado, mientras que las importaciones provenientes del bloque representaron $42 \%$ del total al año 2011 (Ruíz Díaz, 2012: 2). Paraguay es el país que más depende del bloque, ya que su incipiente producción industrial influye en su dependencia de la exportación de bienes primarios y del comercio de reexportación, ${ }^{2}$ principalmente hacia Brasil. Asimismo, Paraguay es el principal beneficiario del Fondo para la Convergencia Estructural del Mercosur (FOCEM), que con el objetivo de disminuir las asimetrías proporciona al Paraguay el $48 \%$ de sus fondos no reembolsables mediante proyectos de inversión. ${ }^{3}$

Finalmente y a pesar de la relativa estabilidad económica observada en los últimos años, resalta el hecho de que los niveles de pobreza, indigencia y desigualdad permanecen altos; mientras los niveles de pobreza e indigencia (Cuadros 2 y 3 ) han disminuido levemente desde 2008, la desigualdad (Cuadro 4) ha aumentado a lo largo del mismo periodo de manera consistente, acentuando la inestabilidad económica de gran parte de la población nacional y socavando los fundamentos de una ciudadanía autónoma en el país, a la vez que potencializan el descontento social.

Se estimó que las reexportaciones alcanzaron los US\$ 4.860 millones en 2011 (Ruiz Díaz, 2012).

El Fondo se integra anualmente con US\$100 millones, de los cuales US\$27 millones provienen de Argentina, US\$ 70 millones provienen de Brasil, US\$ 1 millón proviene de Paraguay y US\$ 2 millones provienen de Uruguay. Paraguay ha logrado, hasta la actualidad, la aprobación e implementación de 19 proyectos de inversión por valor de US\$829 millones. 
Cuadro 2: Evolución de la pobreza 2008-2011 (\%)

\begin{tabular}{lllll}
\hline & 2008 & 2009 & 2010 & 2011 \\
\hline Total país & 37,9 & 35,1 & 34,7 & 32,4 \\
Área urbana & 30,2 & 24,7 & 24,7 & 23,9 \\
Área rural & 48,8 & 49,8 & 48,9 & 44,8 \\
\hline
\end{tabular}

Fuente: DGEEC, Resultados Principales de Pobreza y Distribución del Ingreso, 2012.

Cuadro 3: Evolución de la indigencia 2008-2011 (\%)

\begin{tabular}{lcccc}
\hline & 2008 & 2009 & 2010 & 2011 \\
\hline Total país & 19,0 & 18,8 & 19,4 & 18,0 \\
Área urbana & 10,6 & 9,3 & 10,3 & 10,0 \\
Área rural & 30,9 & 32,4 & 32,4 & 29,6 \\
\hline
\end{tabular}

Fuente: DGEEC, Resultados Principales de Pobreza y Distribución del Ingreso, 2012.

Cuadro 4: Índice de Gini 2008-2011

\begin{tabular}{lcccc}
\hline & 2008 & 2009 & 2010 & 2011 \\
\hline Total país & 0,506 & 0,487 & 0,512 & 0,520 \\
Área urbana & 0,453 & 0,423 & 0,459 & 0,470 \\
Área rural & 0,557 & 0,554 & 0,558 & 0,566 \\
\hline
\end{tabular}

Fuente: DGEEC, Resultados Principales de Pobreza y Distribución del Ingreso, 2012.

\section{TENSIÓN SOCIAL PERSISTENTE Y POLARIZACIÓN DISCURSIVA}

La destitución de Lugo tuvo como antecedente inmediato el enfrentamiento ocurrido entre campesinos y policías en la localidad de Curuguaty en fecha 15 de junio de 2012. Este enfrentamiento estuvo enmarcado dentro de la lucha por el acceso a la tierra protagonizada por grupos de campesinos organizados, que se desarrolla en el país hace más de dos décadas, vinculada a la concentración del 85,5\% de la superficie agropecuaria en 2,6\% de las fincas (MAG, 2009) y a la existencia de más de siete millones de hectáreas de tierras mal habidas (Cuadro 5) -tierras fiscales cedidas durante el gobierno de Stroessner y los sucesivos gobiernos colorados a personas que no deberían ser beneficiarias, según el Estatuto Agrario. ${ }^{4}$ Dado que una de las principales propuestas de campaña de Fernando

4 Una lista de receptores de tierras que no cumplían con las condiciones indicadas en el Estatuto Agrario para ser considerados beneficiarios de la reforma agraria, cuyo sujeto era "la población campesina que no posee tierras o la tiene en forma insuficiente" (CVJ, 2008: 15), se encuentra disponible en el Tomo IV del Informe Final de la Comisión de Verdad y Justicia, Paraguay (2008). Muchas de las personas mencionadas en este Informe, 
Lugo había sido la reforma agraria, el problema que rodea a la tenencia de la tierra se hizo particularmente sensible durante este periodo.

Cuadro 5: Cantidad de tierras adjudicadas en relación con la totalidad de las tierras arables

\begin{tabular}{lcc}
\hline & Hectáreas & Tierras arables $(\%)$ \\
\hline Total & 24.000 .000 & 100 \\
Tierras adjudicadas & 12.229 .594 & 50,1 \\
Tierras malhabidas & 7.851 .295 & 32,7 \\
\hline
\end{tabular}

Fuente: CVJ (2008)

A principios de 2012 se había agudizado el conflicto por la ocupación de tierras en la localidad de Nacunday, departamento de Alto Paraná, donde la agrupación campesina denominada "Liga Nacional de Carperos" se encontraba desde julio del año anterior demandando su expropiación de manos de Tranquilo Favero, colono brasileño ${ }^{5}$ nacionalizado paraguayo. La documentación de respaldo presentada por Favero para indicar su propiedad de esas tierras se contradice con el estudio realizado por la Dirección del Servicio Geográfico Militar (DISERGEMIL), que señala que las mismas pertenecen al Estado. No obstante, esta ocupación ocasionó la fuerte reacción de miembros de la Unión de Gremios de la Producción (UGP) y la Asociación Rural del Paraguay (ARP), principales grupos económicos de presión del país, al punto que uno de sus miembros solicitó a parlamentarios brasileños que intervengan en este conflicto interno (UH, 2011).

La ocupación en Nacunday ganó ímpetu desde el 6 de enero de 2012, fecha en que se dispuso la restitución inmediata de tres inmuebles ocupados por los Carperos a los colonos brasileños Valmir Berle Maholt e Ivani Rubenich Rutsatz. El procedimiento de desalojo de los campesinos de tales tierras estuvo acompañado de mucha atención por parte de la prensa paraguaya, que se encargó de enfatizar discursivamente la naturaleza agresiva de los campesinos y su incidencia negativa en el potencial productivo de los empresarios agroexportadores, ${ }^{6}$ además de criticar el considerado lento accionar del Ministerio del Interior y plantear la existencia de protección gubernamental a las

\footnotetext{
“presidentes de la República, ministros del Poder Ejecutivo, altos funcionarios de gobierno, militares y policías en servicio activo, senadores y diputados, políticos, latifundistas, así como a empresarios e industriales no dedicados a la agricultura ni a la ganadería y que no residen en los lotes y hasta a dictadores perseguidos por la justicia de su país y refugiados por la dictadura paraguaya en el Paraguay" (CVJ, 2008: 207), todavía protagonizan la vida política nacional.

5 De acuerdo con Marcos Glauser (2008), alrededor de 4.800 .000 hectáreas del país estarían en manos de capitalistas y colonos de origen brasileño, entre los que se encuentra Tranquilo Favero, cuya posesión de tierras se encontraría entre seiscientas mil y un millón de hectáreas en todo el país.

6 Referencias de este tipo se registraron desde meses antes del desalojo, cuando se reproducían palabras de dirigentes agroexportadores que argumentaban que "la situación en Alto Paraná ya está fuera de control" (ABC Color, 2011) o se indicaba que "no se descartan nuevos hechos de violencia si los propietarios ingresan con sus vehículos a los inmuebles" (ABC Color, 2011a). Caracterizaciones similares tendrían lugar en los meses siguientes, mediante titulares como "Con prepotencia y sin orden judicial 'carperos' y militares ingresan en
} 
invasiones, que se constituiría luego en uno de los principales argumentos utilizados en el juicio político en contra de Lugo. Por otra parte y según declaraciones del entonces Jefe de Gabinete de la Presidencia, Miguel López Perito, luego del desalojo se denunció la presencia de grupos infiltrados con armas de guerra entre los campesinos (Paraguay. com, 2012), por lo que el gobierno planteó la hipótesis de una pretendida incitación a la violencia armada por parte de terceros.

El conflicto social por la tenencia de la tierra desembocó de manera más crítica en el enfrentamiento ocurrido en Curuguaty el 15 de junio, ocasión en la que perdieron la vida diez campesinos y siete policías. Las tierras públicas ocupadas por los campesinos se encontraban bajo el control de la empresa Campos Morombí S.A.C. y A. de Blas N. Riquelme, ${ }^{7}$ quien había sido parlamentario por el Partido Colorado durante la dictadura de Stroessner y hasta 2008, además de haber ejercido la presidencia de este partido. La versión gubernamental de los hechos indica que un grupo de 70 campesinos, armados con cinco escopetas de caza y un revólver, emboscó a 324 efectivos del grupo de élite de la policía nacional que se acercó al terreno sin armas de fuego, procedimiento que fue foco de crítica de los medios de prensa y de representantes de diversos partidos políticos que sustentó el argumento de que las invasiones campesinas contaban con venia gubernamental.

A pesar de que el informe final presentado por el fiscal Jalil Rachid en octubre da por cerrada la investigación, persisten dudas acerca del enfrentamiento ocurrido en Curuguaty dado que el proceso de investigación fiscal estuvo cubierto por irregularidades. La investigación no tuvo en cuenta que se encontraron casquillos diferentes a los de las armas mencionadas en un primer momento, omisión agravada por la orden de quemar el campamento donde estaban asentados los campesinos, destruyendo toda posibilidad de encontrar mayores pruebas que permitan continuar la investigación. Tampoco se tuvo en cuenta los testimonios de campesinos sobrevivientes al enfrentamiento, quienes señalan que luego del mismo no se proporcionó atención médica a los campesinos caídos, que se detenía a quienes se acercaban a preguntar sobre los heridos y que, posteriormente, fueron sometidos a torturas y asesinatos (CODEHUPY, 2012).

La Plataforma de Estudio e Investigación de Conflictos Campesinos (PEICC, 2012) realizó una investigación independiente al respecto, aunque el informe resultante no tuvo espacio en los principales medios de prensa. A partir de lo observado y escuchado en un video

tierras privadas" (ABC Color, 2012), “Piden desalojar a 'sintierras' violentos de zona de Yvyra Pytã" (ABC Color, 2012a), o "Se estableció ambiente para la violencia, asegura la CAP" (ABC Color, 2012b).

7 Las tierras en cuestión estaban destinadas a la reforma agraria, pero fueron adquiridas de manera irregular durante la dictadura y se encontraban en litigio; las mismas fueron adquiridas del Instituto de Bienestar Rural (IBR) en 1974 por Carlo San José Santacruz y Rodolfo Scolari, miembros del directorio de Campos Morombí S.A.C. y A., quienes luego las transfirieron a Blas N. Riquelme en 1975. Ninguno de los tres podría ser beneficiario de estas tierras según lo indicado por el Estatuto Agrario, dado que eran propietarios de extensiones de tierra que superaban la superficie máxima contemplada en la ley. Por este motivo, se considera que las adjudicaciones hechas por el IBR y los respectivos títulos de propiedad son nulos de nulidad insanable. Además, se establece legalmente que "Las tierras del dominio privado del Estado y de los entes autónomos del Derecho Público no pueden ser adquiridas por usucapión” (Código Civil, Art. 1993), recurso que fue utilizado por Riquelme para resguardar su posesión. 
grabado por la Policía, este informe plantea que se utilizó un fusil automático en el tiroteo además de las armas requisadas, de las cuales sólo una se mostró capaz de disparar, aunque tal evidencia no fue tenida en cuenta por Rachid. El mencionado video también muestra la presencia de mujeres y niños en el lugar del enfrentamiento, lo que pone en duda la hipótesis de la emboscada y se contradice de manera directa con los testimonios de policías involucrados, quienes afirman que en el lugar no había ninguna mujer o niño. En la investigación de la Fiscalía tampoco se menciona la utilización del helicóptero de la policía, dado que los policías entrevistados afirman que este no sobrevolaba el área durante el tiroteo, aunque un video filtrado muestra al helicóptero abriendo fuego (Viana, 2012). Más aún, el médico forense Pablo Lemir manifestó posteriormente que los policías fueron muertos por "disparos de arriba para abajo" y que "la mayoría de los orificios de entrada de los cuerpos de los policías coinciden con las áreas que estaban desprotegidas por los chalecos antibalas (...) con lo que se presume que quien realizó los disparos conocía los lugares que los chalecos no cubrían", aunque tales datos del informe forense tampoco se incluyeron en la presentación de las conclusiones de Rachid. El informe de PEICC también señala que existió manipulación de los cuerpos de los campesinos por parte de los policías. ${ }^{8}$

En todo momento existió predisposición para acusar a los campesinos de ser los únicos culpables de la matanza, a comprender por el accionar de las autoridades encargadas de clarificar lo acontecido. Se encontró posteriormente en el lugar del enfrentamiento una lista que contenía nombres de las personas que lo ocupaban, que había sido elaborada para solicitar víveres a la Secretaría de Emergencia Social del Brasil. Quienes figuraban en esa lista fueron sancionados con prisión preventiva y acusados de homicidio doloso agravado, homicidio doloso en grado de tentativa, lesión grave, asociación criminal, coacción grave e invasión de inmueble ajeno, sin pruebas y sin importar que hayan estado presentes en el momento del enfrentamiento o no, violando sus derechos civiles básicos. ${ }^{9}$ Las catorce personas acusadas ${ }^{10}$ manifiestan haber sido torturadas y amenazadas

8 La entonces Ministra de Salud, Esperanza Martínez, fue hasta Curuguaty para prestar asistencia a las víctimas luego del enfrentamiento. La misma indicó que mientras los cadáveres de los policías habían sido resguardados, los de los campesinos quedaron tirados al lado de la entrada del centro de salud, para luego ser abandonados al momento de transportar a los policías heridos y muertos hasta Asunción. También señaló que los cuerpos de los campesinos fueron llevados para ser sometidos a una autopsia sólo después de que ella amenazó al Fiscal General del Estado con realizar una denuncia internacional (Viana, 2012). Más adelante, durante el juicio político, Esperanza Martínez sería acusada de actuar de manera equivocada en Curuguaty por haber "pretendido tratar de manera igual a policías cobardemente asesinados y a aquellos que fueron protagonistas de estos crímenes" (Libelo Acusatorio, 2012)

9 Según indican Ferreiro y Gorostiaga Guggiari (2012: 363), “La normativa paraguaya establece que una persona puede ser procesada por el Ministerio Público a través de un acta de imputación que debe contener una relación sucinta del hecho punible que se atribuye al procesado. Para aplicar prisión preventiva, el juez o la jueza debe además contar con pruebas que acrediten que el hecho existió y que el procesado, según circunstancias acreditadas, podría realmente ser partícipe del hecho punible que se le atribuye. Además, solo puede aplicarse la privación de la libertad si existe peligro de fuga o de obstrucción de la investigación que sea razonablemente acreditada. El juez o la jueza debe fundar cada uno de estos presupuestos para aplicar lícitamente la medida cautelar de coerción personal de prisión preventiva".

10 Los catorce campesinos acusados son: Rubén Villalba, Felipe Benítez Balmori, Luis Olmedo, Adalberto Castro, Arnaldo Quintana, Néstor Castro, Lucía Agüero, María Fani Paredes y Dolores López Peralta por asociación criminal, invasión de inmueble y homicidio doloso. Por asociación criminal, invasión de inmueble y tentativa 
de muerte, e indican tener pocas esperanzas de ser juzgadas imparcialmente dado que su culpabilidad es un recurso importante que sustenta argumentativamente al juicio político por el que se destituyó a Lugo.

La definición de la investigación y posterior condena fueron protagonizadas por un entramado de actores involucrados en el ejercicio del poder y que mantienen vínculos personales, lo que pone en tela de juicio su imparcialidad y plantea la posibilidad de que existan conflictos de interés en el ejercicio de sus funciones, si bien no existe impedimento legal que las declare incompetentes por tal motivo. En primer lugar, la orden de desalojo de los campesinos llegó como respuesta a la solicitud de Campos Morombí S.A.C. y A. mediante gestión de la fiscala Ninfa Aguilar, quien ya había sido abogada de Blas N. Riquelme en el juicio por usucapión sobre esas tierras. Esta misma fiscala, más adelante, declararía como testigo durante la investigación y posteriormente imputaría a los campesinos como los autores de la matanza, en fecha 16 de diciembre. Por su parte, el diputado Oscar Tuma, quien más adelante redactaría el libelo acusatorio para el juicio político y actuaría como principal fiscal acusador, fue quien solicitó a la Comisión Permanente del Congreso que inste a Carlos Filizzola, entonces Ministro del Interior, a cumplir la mencionada orden de desalojo. Finalmente, la investigación y posterior acusación a los campesinos por la matanza ocurrida fue llevada a cabo por el fiscal Jalil Rachid, hijo del político colorado Bader Rachid Lichi, quien también había sido parlamentario durante el "stronismo", presidente del Partido Colorado y amigo cercano de Blas N. Riquelme.

La matanza de Curuguaty motivó la destitución de Carlos Filizzola del Ministerio del Interior y al nombramiento, en su lugar, del colorado Rubén Candia Amarilla, quien había actuado como Fiscal General del Estado durante el gobierno de Nicanor Duarte Frutos. Ante la negativa de Lugo de ceder el Ministerio del Interior a algún representante del Partido Liberal Radical Auténtico (PLRA) en lugar de Candia Amarilla (ABC Color, 2012c), sus dirigentes optaron por apoyar la iniciativa de juicio político propuesta por el Partido Colorado. De esta manera, la vigésimo cuarta amenaza de juicio político ${ }^{11}$ planteada desde que Lugo asumió la Presidencia de la República en 2008 (Rodríguez González, 2012) se materializó el 22 de junio de 2012, en coincidencia con el clima de conmoción resultante de lo ocurrido una semana antes en Curuguaty.

El impulso al juicio político vino de la mano de diferencias irreconciliables entre posicionamientos políticos respecto de los movimientos campesinos organizados, los cuales reclaman el acceso a la tierra y la reparación histórica que implicaría dar solución

de homicidio doloso: R.V.O. (17). Por asociación criminal: R.A.B.C. (17). Por frustración de la persecución y ejecución penal: Felipe Nery Urbina. Por invasión de inmueble y asociación criminal: Juan Carlos Tillería y Alcides Ramírez Paniagua. Aún quedan varios imputados prófugos.

11 A modo de ejemplo, el senador Alfredo Jaeggli, del PLRA, había indicado ya en 2009 que era necesario sacar a Lugo del gobierno antes de los seis primeros meses, porque pasado ese tiempo se afianzaría en el gobierno (CIPAE, 2009). Jaeggli también había manifestado la diferencia que existe entre un Juicio Político y el Juicio Jurídico: “En el jurídico uno tiene que ser un delincuente, un homicida, se tiene que pillar que mató a alguien; un juicio político, son 30 senadores y 43 diputados que dicen que esto ya no anda más, que no funciona, jasí de fácil es!" (Rodríguez, 2012: 32). 
al problema de las tierras mal habidas, interpelando directamente a los actores políticos que han sido beneficiados por el reparto de tierras desde épocas de la dictadura. El libelo acusatorio planteaba esa dicotomía entre los campesinos y los "ciudadanos honestos" representados por los policías, culpabilizando a los primeros y dispensando completamente a los últimos. Se argumentó que en el país reinaba un clima de inseguridad causado porque Lugo había impulsado la "lucha de clases" e instalado el odio entre los paraguayos, que al apoyar a los campesinos demostraba estar en contra del progreso económico del país y que su "comprobada incapacidad" para erradicar las ocupaciones de tierra ponía al país en riesgo de sumergirse en el caos (Libelo Acusatorio, 2012). También fueron revividas acusaciones surgidas antes de 2008 que vinculaban a Lugo a las FARC, infiriendo que este promovía la guerrilla armada en el país.

Por otra parte, la dimensión urbana del descontento social se había materializado en forma de protestas dirigidas en contra de la labor de los parlamentarios a lo largo del año. La mayor manifestación tuvo lugar el 29 de mayo, cuando la ciudadanía se congregó en torno al Congreso para manifestar su rechazo al pretendido aumento presupuestario del Tribunal Superior de Justicia Electoral (TSJE) -que consistiría en 150.000 millones de guaraníes al TSJE para operadores políticos y de 65.000 millones para inscripción de paraguayos en el extranjero- marcando un hito en la historia de la participación social en el Paraguay, ya que, por primera vez, tuvo resultados sensibles e inmediatos. La multitud autoconvocada por medio de las redes sociales consiguió que el Senado aceptara el veto presidencial a tal ampliación presupuestaria, que había sido aprobada por la Cámara de Diputados, dejándola sin efecto en aquel momento. ${ }^{12}$ Esta victoria ciudadana se constituyó en referente de la importancia de la participación informal y centró la atención en el Poder Legislativo como foco de crítica social, situación que sería desestructurada con la destitución de Lugo.

A su vez, las manifestaciones públicas que ocurrieron frente al Congreso antes y durante el proceso de destitución fueron pacíficas, a pesar de que varios parlamentarios advertían sobre la movilización de "masas violentas" que buscaban promover el caos y la presencia de francotiradores en edificios aledaños a la plaza, e instaban a la población a resguardarse en sus hogares. A pesar de la irregularidad que caracterizó al procedimiento, tampoco se registraron disturbios en los días que siguieron a la destitución de Lugo. No obstante, con el objetivo de descalificar a quienes se manifestaban en oposición a lo ocurrido, fueron revividos adjetivos heredados de épocas de la dictadura -comunistas, izquierdistas, o zurdos, a los que se sumaron los motes de chavistas o luguistas- polarizando el discurso y desalentando a la argumentación en contra de la destitución o la manera en que fue realizado el procedimiento.

La principal manifestación de resistencia ante lo ocurrido fue la huelga de hambre protagonizada por cuatro de los campesinos detenidos por la matanza en Curuguaty, reivindicando su libertad y derecho a la legítima defensa, entre septiembre y noviembre

12 Luego de la destitución de Lugo se lograría la ampliación en el presupuesto de 186 mil millones de guaraníes (cerca de 42 millones de dólares) sobre el monto previsto en el proyecto del presupuesto para 2013, el 29 de octubre. 
de 2012. La huelga de hambre de estos presos políticos estuvo acompañada por una manifestación pública frente a la Fiscalía, cuya represión violenta realizada en la madrugada del 22 de noviembre indica la fragilidad del Estado de Derecho en el país. No obstante, eventualmente se concedió arresto domiciliario a los imputados en huelga citando "razones humanitarias", cuando la medida ya significaba un riesgo severo para sus vidas.

El episodio de Curuguaty se encendería nuevamente el 1 de diciembre de 2012 con el asesinato de Vidal Vega, dirigente campesino e informante clave para las investigaciones paralelas a la del Fiscal Rachid, quien también actuaba como activista en la demanda de esclarecimiento de lo ocurrido en Curuguaty. Su muerte, que tampoco fue clarificada, marca la pauta que el conflicto por la tenencia de la tierra en Paraguay dista de ser resuelto en tanto no se dé una solución al problema de la tenencia de tierras mal habidas, lo que constituiría también una medida de reparación histórica.

\section{IV. ÁMBITO POLÍTICO}

\section{De cara a las elecciones generales de 2013}

La respuesta de la comunidad internacional a la destitución de Lugo consistió en su rechazo generalizado y la falta de reconocimiento de Federico Franco como Presidente legítimo del Paraguay, por lo que se procedió a excluir temporalmente al país de los organismos regionales y multilaterales. Particularmente delicado fue el rechazo de los países del MERCOSUR, estimado como un atropello a la soberanía por las autoridades en ejercicio, por parte de la población identificada con el movimiento nacionalista "Paraguay Soberano" y por el diario ABC Color, cuya labor en la elaboración de argumentos acerca de la intención de los países vecinos de suspender al Paraguay del bloque "tal como habían planeado desde hace tiempo" fue intensiva, dedicando numerosas editoriales y notas a señalar que los "descendientes de Bartolomé Mitre, Pedro II y Venancio Flores", Argentina, Brasil y Uruguay respectivamente, "se vengan rencorosamente del Paraguay por haberse constituido en un obstáculo durante los últimos seis años para que el dictador Chávez ingrese como miembro pleno del Mercosur"13 y "ni siquiera evitan utilizar los mismos argumentos esgrimidos por los aliados en 1865, cuando se confabularon para traer una genocida guerra de exterminio contra la República del Paraguay" (ABC Color, 2012d).

En este contexto, las elecciones generales de 2013 tendrán importancia especial para el país, ya que la percepción que exista sobre la calidad del proceso electoral definirá, en

13 Esta percepción fue reforzada desde el 31 de julio, fecha en que Venezuela se incorporó formalmente al Mercosur como socio pleno. El Congreso paraguayo se había opuesto constantemente al ingreso de Venezuela al bloque debido a diferencias ideológicas con Hugo Chávez, situación agravada desde que Nicolás Maduro, entonces Canciller de Venezuela, se reunió con miembros de la cúpula militar paraguaya antes del juicio político y fue acusado de incitarlos a impedir la remoción de Lugo. Como consecuencia, se instaló el debate acerca de la conveniencia de seguir perteneciendo al bloque, en tanto ocuparon parte importante del discurso las referencias a las trabas comerciales de los países vecinos hacia el Paraguay. 
gran manera, el futuro comercial y diplomático del país. Queda por ver si esta situación particular incidirá en los índices de participación electoral, que si bien se ha mantenido por encima del 60\% desde 1998 en lo que se refiere a la participación efectiva, la proporción disminuye al tener en cuenta a la totalidad de la población en edad de votar (Cuadro 6). El padrón electoral ha aumentado considerablemente desde las últimas elecciones generales, comprendiendo en la actualidad a 3.516 .273 personas habilitadas para votar que estarán en la mira de los partidos y movimientos en competencia.

Cuadro 6: Participación en Elecciones Generales-Poder Legislativo

\begin{tabular}{cccccccc}
\hline Año & $\begin{array}{c}\text { Participación } \\
\text { efectiva }\end{array}$ & $\begin{array}{c}\text { Total de } \\
\text { votos } \\
\text { emitidos }\end{array}$ & $\begin{array}{c}\text { Padrón } \\
\text { Electoral } \\
\text { Nacional }\end{array}$ & $\begin{array}{c}\text { Votos emitidos } \\
\text { / población en } \\
\text { edad de votar }\end{array}$ & $\begin{array}{c}\text { Población } \\
\text { en edad } \\
\text { de votar }\end{array}$ & $\begin{array}{c}\text { Votos no } \\
\text { válidos }\end{array}$ & $\begin{array}{c}\text { Población } \\
\text { total }\end{array}$ \\
\hline 2008 & $65,48 \%$ & 1.874 .127 & 2.861 .940 & $49,86 \%$ & 3.759 .034 & $1,50 \%$ & 6.669 .086 \\
2003 & $64,02 \%$ & 1.539 .800 & 2.405 .108 & $47,47 \%$ & 3.243 .812 & $4,30 \%$ & 5.884 .491 \\
1998 & $80,48 \%$ & 1.649 .419 & 2.049 .449 & $59,38 \%$ & 2.777 .725 & $3,34 \%$ & 5.137 .440 \\
\hline
\end{tabular}

Fuente: International IDEA (2011).

Además de la misma integridad del proceso electoral, el resultado que las elecciones arrojen para ambas cámaras del Poder Legislativo será, más que nunca, clave para la estabilidad del próximo periodo presidencial, ahora que se ha instalado en la práctica de gobierno el recurso del juicio político al Presidente de la República, sin más motivo que la voluntad de los legisladores. La dinámica intrapartidaria se materializará posteriormente en la conformación de bancadas, factor que también puede llegar a incidir en el condicionamiento de su apoyo al Poder Ejecutivo. Al final de 2012, la distribución parlamentaria por partidos y bancadas correspondió a los números presentados en el Cuadro 7.

Sea quien fuere elegido jefe del Poder Ejecutivo, necesitará de fuerte respaldo político en el Congreso si pretende llevar a cabo cualquier plan de gobierno, situación que fue explicitada en la praxis por la dificultad a la que se enfrentó Fernando Lugo para llevar a cabo sus principales promesas de campaña. Además, a pesar de que el Partido Liberal formaba parte de la alianza que lo llevó a la presidencia, al momento del juicio político Lugo contó apenas con el apoyo de cuatro senadores de los cuarenta y cinco que conforman la Cámara Alta, de los cuales uno era liberal, dos del Partido País Solidario (PPS) y uno del Partido Popular Tekojoja (PPT).

También queda por verse hasta qué punto perdurarán las lealtades partidarias en 2013 (Cuadro 8). La volatilidad electoral ${ }^{14}$ se ha mantenido alta desde 1998 (Duarte Recalde,

14 Los niveles de volatilidad electoral son calculados mediante la aplicación del Índice de Pedersen (1983) a los resultados correspondientes a la Cámara Baja de las elecciones de los años 1998, 2003 y 2008, proporcionados por el TSJE. 
Cuadro 7: Distribución parlamentaria por cámaras y bancadas

\begin{tabular}{lcc}
\hline \multicolumn{1}{c}{ Partidos y bancadas } & Senadores & Diputados \\
\hline ANR & 15 & 34 \\
Bancada A & 8 & 7 \\
Bancada B & 4 & 21 \\
Bancada C & 3 & \\
Independientes & 14 & 29 \\
PLRA & 14 & 15 \\
Bancada única & & 14 \\
Bancada B & & 11 \\
Bancada B & 9 & 4 \\
UNACE (bancada única) & 4 & \\
PPQ (bancada única) & 2 & 1 \\
PPS & 1 & 1 \\
PPT & 3 & \\
Multibancada PPS-PPT & & \\
PPC (bancada única) & & \\
PDP (bancada única) & & \\
\hline
\end{tabular}

Fuente: Cámara de Senadores y Diputados.

Cuadro 8: Proporción de votos obtenidos por partido en las últimas elecciones generales

\begin{tabular}{lrrr}
\hline & 1998 & 2003 & 2008 \\
\hline ANR & 0,52 & 0,34 & 0,31 \\
PLRA & 0,41 & 0,25 & 0,27 \\
PEN & & 0,03 & 0,01 \\
PPQ & & 0,15 & 0,05 \\
UNACE & & 0,14 & 0,18 \\
PPS & 0,03 & 0 \\
PPL & 0,01 & 0 \\
PHP & & 0 & 0,02 \\
P-MAS & & & 0 \\
PT & & & 0 \\
PUP & & & 0,03 \\
MPT & & & 0,02 \\
PDP & & 0,02 & 0,05 \\
Otros & 0,03 & 0,04 & 0,06 \\
Nulos / Blancos & 0,03 & & 0 \\
\hline
\end{tabular}

Fuente: Elaboración propia, a partir de datos del Tribunal Superior de Justicia Electoral 
2012), llegando al 35\% a lo largo de los tres últimos periodos electorales, indicando la alta probabilidad que existe de que los votantes paraguayos se posicionen electoralmente de manera diferente entre un periodo y el siguiente, en coincidencia con la fragmentación de las preferencias electorales tradicionales colorada y liberal, así como la falta de afianzamiento de nuevas identidades políticas.

Sin embargo, se mantiene el dominio bipartidista ANR-PLRA que ha caracterizado a la historia del Paraguay, ${ }^{15}$ mismo cuando la ANR ha perdido proporciones de votos de manera progresiva desde 1998, a pesar de seguir siendo el partido con mayor representación en el Congreso, en tanto que la captación de votos por parte del PLRA ha mostrado tendencia fluctuante.

Luego de 2008, la posición de tercera fuerza electoral quedó en manos del partido Unidad Nacional de Ciudadanos Éticos (UNACE), escisión de la ANR, aunque el regreso de sus parlamentarios y afiliados hacia su partido de origen (LN, 2011) puede volcar la balanza a favor de la ANR nuevamente. Por otra parte, el posicionamiento de los votantes no alineados a ninguno de los partidos mencionados puede llegar a ser clave en el resultado final de las elecciones, considerando que los mismos representaron más del $12 \%$ de los votos en 2008 .

\section{Elecciones internas}

La segunda mitad de 2012 estuvo marcada por el debate precedente a las internas partidarias, que se celebrarían entre diciembre de 2012 y enero de 2013. Con la novedad de haberse habilitado mesas de votación fuera del país, las internas partidarias se desarrollaron dentro de la dinámica tradicional de denuncias de fraude e incidentes en todo el territorio del país, entre los que estuvieron la presencia de propaganda electoral fuera del plazo determinado, utilización de recursos estatales (Palorubin.com, 2012) y coacción a funcionarios públicos con fines electorales (Sanlorenzopy.com, 2012), desaparición de papeletas de votación (UH, 2012c), posesión de cédulas de identidad de varias personas (LN, 2012a) y arreo de votantes (UH, 2012d), e incluso violencia física (UH, 2012; 2012a y 2012b). Al considerar la regularidad con que se cometen delitos electorales, la Fiscal Electoral Norma Cristaldo manifestó que algunos artículos del Código Electoral deberían, simplemente, ser derogados (LN, 2012).

La interna partidaria más importante fue la de la ANR, cuyo resultado decidiría quién representaría a este partido en la puja por retomar la presidencia perdida en 2008 ante la Alianza Patriótica para el Cambio, cuando se puso pausa a su dominio del Poder Ejecutivo de más de seis décadas. Las candidaturas para los diferentes cargos se mantuvieron protagonizadas por las mismas personas vinculadas a la política nacional incluso desde el periodo "stronista", con la gran excepción de Horacio Cartes, candidato a la Presidencia de la República que terminaría resultando victorioso.

15 El bipartidismo en Paraguay se remonta a 1887, año en que fueron fundados la ANR y el PLRA. Ambos partidos, además de ser los más tradicionales en Paraguay, han establecido fuertes vínculos entre su administración y la población mediante relaciones clientelares. 
Vinculado a denuncias de lavado de dinero, evasión de divisas, falsificación de documentos, estafa, contrabando y narcotráfico, Horacio Cartes es el outsider que se posicionó como figura de liderazgo dentro del Partido Colorado luego de su derrota electoral en 2008. Su incursión en la política ha estado acompañada por la presencia de Francisco Javier Cuadra, ex-vocero y ministro de Augusto Pinochet, quien ya hubiera trabajado como asesor comercial de Cartes durante más de una década. Cartes reconoció que nunca votó en elecciones generales y que apenas se inscribió en el Registro Permanente en 2009, a los 59 años de edad. No obstante, consiguió que el partido modifique sus estatutos para poder ser su candidato, a pesar de tener menos de cinco años de afiliación. La llegada de Cartes al Partido Colorado significó un importante influjo de recursos económicos que ya fueron utilizados para las elecciones municipales de 2010 y en las internas para la presidencia del Partido Colorado de 2011, en que resultó victoriosa su candidata Lilian Samaniego.

Las internas coloradas se caracterizaron nuevamente por la ausencia del debate entre candidatos, consecuencia principalmente de la negativa de Cartes a discutir su plataforma en vivo. No obstante, una novedad en la praxis electoral que estas internas presentaron consistió en la apertura de las listas de candidatos para los órganos colegiados, liderada por el movimiento Honor Colorado, aunque la mayoría de los movimientos aún presentaron listas cerradas y candidaturas con órdenes preestablecidos. Esta estrategia permitió que los candidatos seleccionados reflejen mejor las preferencias de los colorados, a la vez que ayudó a Honor Colorado a evitar la fuga de votos hacia candidatos de otros movimientos.

A su vez, las internas del PLRA realizadas el 16 de diciembre, oportunidad en que se ratificó a Efraín Alegre como candidato a Presidente, estuvieron cubiertas por un halo de irregularidad. Los acuerdos previos entre miembros de la élite partidaria se materializaron en listas oficiales que pretendieron ser ratificadas en las urnas, aunque se inscribieron nueve listas para senadores, setenta y cuatro para diputados, cinco para el Parlasur y ocho para la titularidad del partido. Los resultados coincidieron con lo esperado por el oficialismo, aunque luego fueron judicializados por denuncias de fraude. Sectores del partido que se sienten contrariados han amenazado con no trabajar en apoyo del PLRA con miras a abril de 2013, situación que puede restarles votos y dañar su imagen ante el electorado independiente.

La cohesión del PLRA también sigue siendo cuestionada como resultado de la división ocurrida luego del 1 abril de 2012, cuando se realizó una encuesta que pretendía determinar al candidato mejor posicionado con miras a 2013. Con el objetivo de evitar el desgaste de la competencia en internas partidarias y advertir las preferencias del electorado interno y extrapartidario, Efraín Alegre, Blas Llano y Federico Franco establecieron un "pacto de caballeros" que manifestaba su voluntad de respetar los resultados de una encuesta que sería realizada a domicilio, procedimiento que recibió el apodo de "urnas delivery" en la prensa nacional. Llano, quien era senador, ex-ministro de Justicia y Trabajo y Presidente del partido, se enfrentó a Alegre, senador y ex-ministro de Obras Públicas y Comunicaciones, cuya labor generalmente aprobada coexiste con acusaciones de utilización de recursos estatales con fines proselitistas. Franco, entonces vicepresidente de la República, era el tercer candidato en disputa y fue el primero en reconocer su derrota en la encuesta. 
A pesar de que los sondeos de boca de urna favorecían a Alegre, Llano sería proclamado ganador una semana después, lo que despertó acusaciones de fraude por parte de Alegre y produjo en el partido una división que parecía insuperable.

De esta manera, el consenso acerca de la candidatura de Alegre no deja de ser puesta en tela de juicio, aunque en la actualidad se pregona la aparente superación de diferencias al interior del partido. Alegre tiene como compañero de fórmula a Rafael Filizzola, que había sido anteriormente Ministro del Interior. Filizzola es miembro del Partido Democrático Progresista (PDP), afín a la socialdemocracia, cuyas internas para la ratificación de su candidatura se celebraron en la misma fecha. Los liberales reconocen que para ganar las elecciones de 2013 dependerán de las alianzas estratégicas, aunque cargan con el peso simbólico de haber apoyado la destitución del primer Presidente no colorado en décadas, por lo que la posibilidad de pactar con el electorado que rechaza la destitución de Lugo se ve difícil.

A pesar de que tienen a su disposición los recursos estatales, las chances liberales también se ven obstaculizadas por la gestión de Federico Franco al frente del Poder Ejecutivo, repudiado en actos públicos en numerosas oportunidades ( $E^{\prime} a, 2012 b$ ), que dentro de su limitación temporal ha demostrado un estilo primordialmente oportunista. Además de capitalizar las obras realizadas durante el gobierno de Lugo, desde que Franco asumió la presidencia ha solicitado incrementos presupuestarios para el Poder Ejecutivo que "dejará a nuevos gobiernos millonarias deudas a pagar" ( $\mathrm{UH}, 2013)$, ha incurrido en constantes prácticas de nepotismo, al punto que actualmente cerca de treinta de sus parientes se encuentran trabajando en la función pública (El Mundo, 2012), a la vez que ubicó a sus correligionarios en el lugar de más de dos mil funcionarios públicos de otros partidos, según ha denunciado la Confederación de la Clase Trabajadora (Globedia.com, 2012). Su gestión también tiene trazos de autoritarismo, en consideración de la dispersión por la fuerza de quienes se manifestaban frente al Congreso al momento de destitución de Lugo, de su inmediata intervención en la Radio Nacional del Paraguay y la TV pública luego de haber asumido, del decreto firmado que habilita la liberación de entrada y siembra de semillas transgénicas sin reparo de sus potenciales efectos ambientales o sociales, o de su premura al posibilitar la instalación en el país de la empresa Río Tinto Alcán y cederle energía a un precio diferenciado fijo por 30 años, sin haberse realizado estudios de impacto ambiental. Los mencionados casos denotan la escasa predisposición de Franco al diálogo intersectorial, que podría trasladarse al rechazo de los demás sectores políticos a establecer alianzas electorales con su partido.

En coincidencia con las internas del PLRA y del PDP se llevaron a cabo las internas del Partido Patria Querida (PPQ) para la elección de candidatos a órganos colegiados, para las cuales se desbloquearon todas las listas. La candidatura de Miguel Carrizosa para Presidente de la República también había sido previamente acordada, luego de que este haya sido derrotado dos veces como candidato a intendente de Asunción. Junto con Arsenio Ocampos -candidato a la vicepresidencia, ex-senador y actual secretario general del partido-Carrizosa pretende recrear el apoyo electoral que el partido consiguió una década antes de la mano de Pedro Fadul, que ha declinado progresivamente. 
Por su parte, las internas del Partido UNACE se realizaron el 23 de diciembre. En esa ocasión se oficializó la candidatura a la Presidencia de la República de Lino Oviedo, figura carismática alrededor de la cual se formó el mismo partido, quien hubiera estado presuntamente vinculado al intento de golpe de Estado en 1996, el asesinato del vicepresidente Luis María Argaña y la matanza de jóvenes en el "Marzo Paraguayo". ${ }^{16}$ El partido venía perdiendo afiliados y dirigentes a favor de la ANR en los últimos meses, atraídos por Horacio Cartes, por lo que las elecciones generales podrían haber definido de una vez por todas la viabilidad de este partido a largo plazo. Sin embargo, un accidente aéreo ocurrido en la noche del sábado 2 de febrero de 2013 acabó con la vida de Lino Oviedo, quien se encontraba en campaña proselitista, por lo que el futuro del partido es más incierto aún. Ante este escenario, una eventual alianza entre la coalición que impulsa la candidatura de Efraín Alegre y el UNACE afianzaría el apoyo oficial de este último partido a favor del liberal, aunque esto no implique necesariamente que el electorado oviedista se posicionará en las urnas como bloque, siguiendo las indicaciones de los líderes coyunturales del partido.

Las elecciones internas de los partidos y movimientos de izquierda ocurrirían recién en enero de 2013. En las mismas se ratificó las candidaturas de Mario Ferreiro al frente del movimiento Avanza País, ${ }^{17}$ de Aníbal Carrillo como referente del Frente Guasu ${ }^{18}$ y de Lilian Soto al frente del Movimiento Kuña Pyrenda, ${ }^{19}$ principales exponentes de este sector que fuera base de apoyo político al gobierno de Lugo. La izquierda terminó 2012 dividida al no haberse logrado un acuerdo para la presentación de candidaturas conjuntas, por lo que no representan una alternativa electoral con posibilidades reales de volver al frente del Poder Ejecutivo.

Mario Ferreiro es la figura más conocida entre los tres, habiendo trabajado como periodista durante más de treinta años en diferentes medios de comunicación, por lo que podría captar votos tanto de la izquierda como del sector independiente a pesar de ser otro outsider recién llegado a la política. Aníbal Carrillo, médico y militante de larga data, cuenta con el apoyo de Fernando Lugo y la fuerza electoral que este le proporciona al candidatearse para el Senado, aunque su fuerte identificación ideológica de izquierda lo hace un candidato con menos probabilidades de atraer al electorado independiente. Lilian Soto, por su parte, cuenta con el respaldo de su gestión al frente de la Secretaría de la Función Pública durante el gobierno de Lugo y gran experiencia de trabajo en

Como consecuencia del asesinato de Luis María Argaña en 1999, miles de personas se congregaron en la plaza frente al Congreso demandando la renuncia del entonces presidente Raúl Cubas. En la manifestación se produjeron enfrentamientos entre grupos detractores y partidarios de Oviedo, hasta que el ataque de francotiradores del 26 de marzo culminó en la muerte de siete jóvenes que se encontraban entre los manifestantes en contra del gobierno.

17 El movimiento Avanza País está conformado por los partidos Movimiento al Socialismo (P-MAS), Revolucionario Febrerista (PRF), Demócrata Cristiano (PDC), Paraguay Tekopyahu y el Movimiento Político 20 de Abril (M20A).

18 El Frente Guasu está formado por las agrupaciones País Solidario (PPS), Tekojoja (PPT), Movimiento Patriótico Popular (MPP), Frente Amplio (PFA), Partido Comunista Paraguayo (PCP), Partido de la Unidad Popular (PUP), Convergencia Popular Socialista (PCPS) y Participación Ciudadana (PPC).

19 Palabras que significan "plataforma de mujeres" en guaraní, Kuña Pyrenda es el primer movimiento político en postular a cinco mujeres indígenas provenientes de distintas etnias para cargos electivos. 
organizaciones sociales al liderar el primer movimiento electoral feminista, que tiene como bandera política la lucha por la igualdad de género en un país en que el machismo es endémico. Así, estos tres candidatos dividen los posicionamientos electorales de izquierda, ya que no han logrado acordar un mecanismo que defina la chapa presidencial en conjunto, lo que permitiría agregar sus votos y tener mayores posibilidades de lograr su representación legislativa, si bien no la presidencia.

Una de las últimas encuestas realizadas en 2012 (UH, 2012e) acerca de la intención de voto indicaba que 37,8\% votaría por Horacio Cartes, 31,1\% por Efraín Alegre, $9 \%$ por Mario Ferreiro, 8,1\% por Aníbal Carrillo, 5,2\% por Lino Oviedo, 2,1\% por Miguel Carrizosa y 0,6\% por Lilian Soto. Así, al finalizar 2012 la ANR era la agrupación que se presentaba con mejores posibilidades de ganar las elecciones, situación que puede ser revertida si se llegan a concretar alianzas estratégicas entre las demás candidaturas contendientes.

\section{CONSIDERACIONES FINALES SOBRE CALIDAD DE LA DEMOCRACIA}

En 2012, en Paraguay se interrumpió el proceso de consolidación de la democracia que se había hecho aparente luego de 2008, cuando se designó por vía electoral a un Presidente de la República no Colorado sin que esto implique un desequilibrio social o institucional en aquel momento. Al tener en cuenta la manera en que las principales representaciones políticas respondieron ante el conflicto social generado por la concentración de la tierra en el país, optaron por identificar a Fernando Lugo como responsable de todo lo ocurrido y proceder a su destitución, ha quedado claro el predominio institucional que mantiene el Poder Legislativo frente al Ejecutivo, el amplio margen de discrecionalidad con que se toman las decisiones políticas sin que funcione un mecanismo de rendición de cuentas social efectivo, así como la intolerancia ideológica que caracteriza a parte de la sociedad paraguaya. La imposibilidad de establecer un diálogo político sin caer en dicotomías discursivas extremas indica la escasa predisposición que existe en el país para convivir en democracia, así como la dificultad para profundizarla.

De esta manera, la democracia paraguaya se limita a su dimensión mínima (Morlino, 2011) y en gran manera sigue reducida a su dimensión procedimental. Lo ocurrido en 2012 enfatizó su carácter ineficiente, teniendo en cuenta la subordinación del Poder Judicial a intereses sectarios que desembocan en la persistente duda acerca de lo ocurrido en Curuguaty, sustentada en la irregularidad con que procedió la investigación de la Fiscalía. El carácter ineficiente de la democracia se percibe, además, en la utilización de fuerza policial para reprimir a la protesta social que se hizo sensible en los días siguientes a la destitución de Lugo.

Por otra parte, 2012 expuso el carácter desigual de la democracia paraguaya, en consideración a la persistente proporción de la población en situación de pobreza e indigencia, los altos niveles de desigualdad, la inequitativa tenencia de la tierra y las consecuencias conflictivas que tales factores acarrean. Los acontecimientos ocurridos en Curuguaty y sus secuelas son signos de que mientras no haya iniciativas gubernamentales concretas que tiendan hacia una reforma agraria integral, no se dará solución al principal foco de 
conflicto social del país, que es el campo. A su vez, la enardecida criminalización de la protesta campesina plantea un horizonte incierto para el respeto a los derechos humanos en el país en el futuro cercano.

El gobierno de Fernando Lugo, si bien no estuvo ajeno a errores en su gestión, en gran manera resultó víctima de la miopía en el ejercicio del poder que caracterizó al exmandatario y a sus colaboradores cercanos en el gobierno. Los mismos no fueron capaces de capitalizar la estabilidad macroeconómica en que se encuentra el país como base para mayor apoyo popular, a pesar de las dificultades que implicaron el cierre de mercados internacionales a la carne o la sequía que afectó al país. Su mayor expresión de miopía, no obstante, consistió en no ceder ante el pedido puntual del PLRA de quedar al frente del Ministerio del Interior luego de los sucesos de Curuguaty. Sea por exceso de confianza o subestimación de las repetidas amenazas de juicio político, su falta de experiencia en la gestión del poder se hizo sensible y facilitó que Fernando Lugo asumiera el rol de chivo expiatorio por todos los problemas del país, explotando la tradición excesivamente delegativa (O'Donnell, 1994) de la democracia paraguaya.

A pesar de las múltiples debilidades que caracterizan a la democracia paraguaya, la alternancia obtenida al frente del Poder Ejecutivo en 2008 implicó un paso importante en la consolidación de la praxis democrática, al menos en lo que respecta a la atención a las reglas del juego de la competencia política; la entrega pacífica del poder por parte de la ANR a un candidato de concertación representaba una novedad en la historia política del país, que vino a reforzar la conquista de libertades civiles y políticas alcanzadas desde la caída de la dictadura. Por este motivo, al haber destituido de manera irregular al Presidente de la alternancia, se ha puesto en duda la misma viabilidad del modelo procedimental democrático, ya que no parecen existir garantías de estabilidad al frente del Poder Ejecutivo si no se cuenta con apoyo mayoritario en el Legislativo. Se ha interrumpido la consolidación de la democracia también en sus dimensiones de contenido, ya que la atención del gobierno a respetar las libertades civiles o a combatir la desigualdad entre la población ha cedido espacio ante iniciativas que apuntan a velar por intereses sectarios. Finalmente, se ha interrumpido la consolidación de la democracia en Paraguay al haberla reducido a un procedimiento legal, en un país donde la vigencia del Estado de Derecho sigue siendo, para amplios sectores de la población, una materia pendiente.

\section{REFERENCIAS}

ABC Color. 2011. "Alto Paraná está que arde; no tenemos el control". [En línea] http://www.abc.com. py/nacionales/alto-parana-esta-que-arde-no-tenemos-el-control-282213.html [Consulta: 12-7-2011]. 2011a. "Policía se prepara para desalojo en Ñacunday". [En línea] http:/ /www.abc.com.py/nacionales/ policia-sepreparapara-desalojo-en-nacunday-282759.html [Consulta: 13-7-2011].

2012. "Con prepotencia y sin orden judicial 'carperos' y militares ingresan en tierras privadas". [En línea] http:/ /www.abc.com.py/nacionales/con-prepotencia-y-sin-orden-judicial-carperos-ymilitares-ingresan-en-tierras-privadas-358352.html [Consulta: 23-1-2012].

2012a. "Piden desalojar a 'sintierras' violentos de zona de Yvyra Pytã". [En línea] http://www. abc.com.py/edicion-impresa/interior/piden-desalojar-a-sintierras-violentos-de-zona-de-yvyrapyt-407924.html [Consulta: 30-5-2012]. 
2012b. "Se estableció ambiente para la violencia, asegura la CAP". [En línea] http:/ / www.abc.com. py/edicion-impresa/politica/se-establecio-ambiente-para-la-violencia-asegura-la-cap-415706.html [Consulta: 19-6-2012].

2012c. "El PLRA exige a Lugo destitución de Candia Amarilla para no apoyar juicio". [En línea] http:/ /www.abc.com.py/edicion-impresa/politica/el-plra-exige-a-lugo-destitucion --de-candiaamarilla-para-no-apoyar-juicio-416149.html [Consulta: 20-6-2012].

2012d. "Una nueva Triple Alianza se venga del Paraguay". [En línea] http://www.abc.com.py/ edicion-impresa/editorial/una-nueva-triple-alianza-se-venga-del-paraguay-420605.html [Consulta: 30-6-2012].

Banco Central del Paraguay (BCP). 2012. Informe Económico Preliminar 2012. Asunción.

Coordinadora de Derechos Humanos del Paraguay (CODEHUPY). 2012. "La matanza de Curuguaty". En Derechos humanos en el Paraguay 2012. Asunción: CODEHUPY, 583-590.

Comisión de Verdad y Justicia, Paraguay (CVJ). 2008. Informe Final. Tomo IV. Parte I. Asunción: Comisión de Verdad y Justicia.

Comité de Iglesias para Ayudas de Emergencia (CIPAE). 2009. "Situación de los Derechos Humanos en el Paraguay". [En línea] http:/ / www.cipae.org.py/V2/uploads/2010/03/derechos -humanos-2009111. pdf [Consulta: 20-1-2013].

Dirección General de Estadística, Encuestas y Censos (DGEEC). 2012. Encuesta Continua de Empleo: 3er trimestre 2012. [En línea] http:/ / www.dgeec.gov.py/Publicaciones /Biblioteca/ECE2012/Boletin_ ECE-3er\%20trim\%202012.pdf [Consulta: 20-1-2013].

Duarte Recalde, Liliana Rocío. 2012. "Variaciones en el Comportamiento Electoral en Paraguay". América Latina Hoy 60 (1): 117-138.

E'a. 2012. "Manifestaciones por la restauración democrática se realizarán en todo el país". [En línea] http://ea.com.py/manifestaciones-por-la-restauracion-democratica-se-realizaran-en-todo-el-pais/ [Consulta: 26-6-2012].

2012a. "Manifestaciones internacionales contra el golpe parlamentario en Paraguay". [En línea] http:/ /ea.com.py/manifestaciones-internacionales-en-contra-del-golpe-parlamentario-en-paraguay/ [Consulta: 28-6-2012].

2012b. "Federico Franco: ningún presidente fue más 'escrachado' en la historia del país". [En línea] http:/ /ea.com.py/federico-franco-el-presidente-que-mas-escrachado-en-la-historia-del-pais/ [Consulta: 28-6-2012].

Duré, Elizabeth; Ortega, Guillermo; Palau, Marielle y Rojas Villagra, Luis. 2012. Golpe a la democracia: Antecedentes y Perspectivas. Asunción: BASE-IS.

El Mundo. 2012. “Un total de 27 familiares del presidente paraguayo ocupan cargos públicos". [En línea] http:/ / www.elmundo.es/america/2012/09/17/noticias/1347896747.html [Consulta: 17-9-2012].

Ferreiro, Guillermo y Gorostiaga Guggiari, Katia. 2012. "Cuando la Libertad no Vale Nada”. En Coordinadora de Derechos Humanos del Paraguay (CODEHUPY). Derechos humanos en el Paraguay 2012. Asunción: CODEHUPY, 363-369.

Glauser, Marcos. 2009. Extranjerización del territorio paraguayo. Asunción: BASE-IS.

Globedia.com. 2012. "Paraguay: CCT denuncia la política de persecución impulsada sindical". [En línea] http://py.globedia.com/paraguay-cct-denuncia-politica-persecucion-impulsada-sindica [Consulta: 20-7-2012].

International Institute for Democracy and Electoral Assistance (International IDEA). 2011. "Voter Turnout Data for Paraguay". [En línea] http://www.idea.int/vt/countryview.cfm?id=186, [Consulta: 20-1-2013].

La Nación (LN). 2011. "Progresivo desmantelamiento del UNACE: 250 a 300 oviedistas retornan por semana a filas de la ANR". [En línea] http:/ / www.lanacion.com.py/articulo.php?250-a-300-oviedistasretornan-por-semana-a-filas-d\&edicion=2\&sec=1\&art=25434 [Consulta: 3-6-2011].

2012. "Innumerables delitos electorales". [En línea] http:/ / www.lanacion.com.py/articulo/103702-gt-gt-nbspinnumerables-delitoselectorales.htm [Consulta: 9-12-2012].

2012a. "Lo detuvieron con 50 cédulas". [En línea] http:/ / www.lanacion.com.py/articulo/103727lo-detuvieron-con-50-cedulas.html [Consulta: 9-12-2012]. 
Libelo Acusatorio. 2012. [En línea] http:/ /www.europarl.europa.eu/meetdocs/2009_2014/ documents/ dmer/dv/libelo_acusatorio_contra_lugo_/libelo_acusatorio_contra_lugo_es.pdf [Consulta: 20-1-2013].

Ministerio de Agricultura y Ganadería (MAG). 2009. Resultados Preliminares del Censo Agropecuario Nacional 2008. [En línea] http:/ / www.mag.gov.py/PresentacionCAN2008.pdf [Consulta: 20-1-2013].

Morlino, Leonardo. 2011. Changes for Democracy. Oxford: Oxford University Press.

O'Donnell, Guillermo. 1994. "Delegative Democracy". Journal of Democracy 5: 55-69.

Palorubin.com. 2012. "La mayor puja electoral se concentrará en la Capital, Central y el Alto Paraná". [En línea] http:/ / www.palorubin.com/noticias.php?id2=81708 [Consulta:9-12-2012].

Paraguay.com. 2012. "No sé por qué el jefe y el sub jefe del GEO encabezaban la comitiva". [En línea] http:/ /www.paraguay.com/nacionales/-no-se-por-que-el-jefe-y-el-sub-jefe-del-geo-encabezabanlacomitiva-83542 [Consulta: 16-6-2012].

Pedersen, Morgens. 1983. “Changing Patterns of Electoral Volatility in European Party Systems, 1948-1977: Explorations in Explanations". En Western European Party Systems: Continuity and Change, Daalder, Hans y Mair, Peter. Beverly Hills: Sage, 29-66.

Plataforma de Estudio e Investigación de Conflictos Campesinos (PEICC). 2012. "Informe Masacre de Curuguaty". [En línea] http://www.scribd.com/doc/110616439/Informe-Curuguaty-PEICC, [Consulta: 29-12-2012].

Rodríguez González, Fátima Elizabeth. 2012. "Paraguay 2012: Crónica de un juicio político anunciado". [En línea] www.apeparaguay.org [Consulta: 20-1-2013].

Ruiz Díaz, Francisco. 2012. "¡Ser o no Ser! El dilema del Paraguay en el Mercosur". [En línea] http:// www.cadep.org.py/uploads/2012/07/Art\%C3\%ADculo-FRD-imp.pdf [Consulta: 16-7-2012]. Sanlorenzopy.com. 2012. “Denuncian a Albino Ferrer por Coerción Electoral”. [En línea] http:/ / www. sanlorenzopy.com/12878/denuncian-a-albino-ferrer-por-coaccion-electoral/ [Consulta: 7-11-2012].

Subsecretaría de Estado de Tributación (SET). 2012. "Fisco registra 39 mil nuevos contribuyentes". [En línea] http:/ / www.set.gov.py/pset/hgxpp001?,18,273,O,S,0,PAG;CONC;359;2;D;5075; 1;PAG;MNU; E;139;1 ;MNU [Consulta: 6-2-2013].

2012a. "Recaudación de la Administración Tributaria aumentó 11,8\% en todo el 2012". [En línea] http:/ / www.set.gov.py/pset/hgxpp0016,18,273, O,S,0,PAG;CONC;240;1; D; 5122;1;PAG [Consulta: 6-2-2013].

Última Hora (UH). 2011. "La UGP minimiza pedido de auxilio hecho por colono". [En línea] http:// www.ultimahora.com/notas/447391-La-UGP-minimiza-pedido-de-auxilio--hecho-por-colono [Consulta: 20-1-2013].

2012. "Seis personas son detenidas por el asesinato del político sampedrano". [En línea] http:// www.ultimahora.com/notas/581454-Seis-personas-son-detenidas-por-el-asesinato-del-politicosampedrano [Consulta: $30-11-2012]$.

2012a. "A pedradas y golpes en Lambaré". [En línea] http:/ / www.ultimahora .com/notas/583852Intendente-de-Lambare-denuncia-agresion-contra-sus-hijos- [Consulta: 9-12-2012].

2012b. "Concejal de Mariscal Estigarriba denuncia atropello de grupo liderado por intendente". [En línea] http:/ / www.ultimahora.com/notas/583937-Concejal-de-Mariscal-Estigarriba-denunciaatropello-de-grupo-liderado-por-intendente [Consulta: 9-12-2012].

2012c. "Denuncian desaparición de más de 712 papeletas en Itapúa". [En línea] http:/ / www.ultimahora. $\mathrm{com} /$ notas/583854-Denuncian-desaparicion-de-mas-de-712-papeletas-en-Itapua [Consulta: 9-12-2012]. 2012d. "Hasta G. 10 millones por arrear indígenas en el Chaco". [En línea] http:/ / www.ultimahora. $\mathrm{com} /$ notas/585757-Hasta-G.-10-millones-por-arrear-indigenas-en-el-Chaco [Consulta: 16-12-2012]. 2012e. "El 28\% de encuestados de GEO creen que Lugo sigue apoyando a Ferreiro". [En línea] http:/ / www.ultimahora.com/notas/588181-El-28\%20-de--encuestados-de-GEO-creen-que--Lugo-sigueapoyando-a--Ferreiro [Consulta: 27-12-2012].

2013. “El Banco Central abre nuevo canal para que Hacienda acceda a créditos". [En línea] http:// www.ultimahora.com/notas/609517-El-Banco-Central-abre-nuevo-canal-para-que-Hacienda-accedaa-creditos [Consulta: 23-03-2013].

Viana, Natalia (2012), “Curuguaty, a matança que derrubou Lugo". [En línea] http:/ /www.apublica. org/2012/11/curuguaty-matanca-derrubou-lugo/ [Consulta: 28-1-2013]. 
Liliana Rocío Duarte Recalde. Investigadora Asociada al Centro de Políticas Públicas de la Universidad Católica "Nuestra Señora de la Asunción".

E-mail: rociohk@yahoo.com 